\title{
QUANTIFICATION OF CHANGES IN METAL LOADING FROM STORM RUNOFF, MERSE RIVER (TUSCANY, ITALY)
}

\author{
Briant A. Kimball ${ }^{1}$,Francesco Bianchi ${ }^{2}$, Katherine Walton-Day ${ }^{3}$, Robert L. Runkel, \\ Marco Nannucci ${ }^{4}$ and Andrea Salvadori ${ }^{4}$ \\ ${ }^{1}$ U.S. Geological Survey, Salt Lake City, Utah 84119, USA \\ ${ }^{2}$ Via Delle Masse 65, 50141 Firenze, Italy \\ ${ }^{3}$ U.S. Geological Survey, Denver, Colorado 80225, USA \\ ${ }^{4}$ Regione Toscana, Piazza della Resistenza 54, 5110, Pistoia, Italy
}

\begin{abstract}
Impacts in streams from mine and mine-waste drainage present challenges for remediation. The Merse River in Tuscany is affected by both mine drainage and the weathering of mine wastes throughout its catchment. Quantification of metal loading to the stream is one of the first steps to understanding options for remediation. During the course of a field experiment to evaluate metal loading to the Merse, data were obtained for storm and pre-storm conditions, providing a unique opportunity for comparison. Copper and manganese were chosen to illustrate changes resulting from the storm. Total-recoverable loads of both metals increased during the storm runoff; $\mathrm{Cu}$ by over 70 times and $\mathrm{Mn}$ by more than 9 times. Increases were a result of flushing particulates from near the stream, resuspension of colloidal material from the streambed, and increased ground-water inflow to the stream. The greater increase in $\mathrm{Cu}$ load results from its association with colloidal $\mathrm{Fe}$. Manganese increases were likely a result of increased ground-water inflow during the storm. Despite great increases in load, the filterable concentrations of these metals did not increase substantially, remaining below chronic levels of toxicity.
\end{abstract}

\section{Introduction}

The Merse River, located in southern Tuscany (Fig. 1), has been affected by centuries of mining (Benvenuti et al., 1997). Currently (2007), mine drainage is being treated before being discharged to Fosso di Ribudelli,

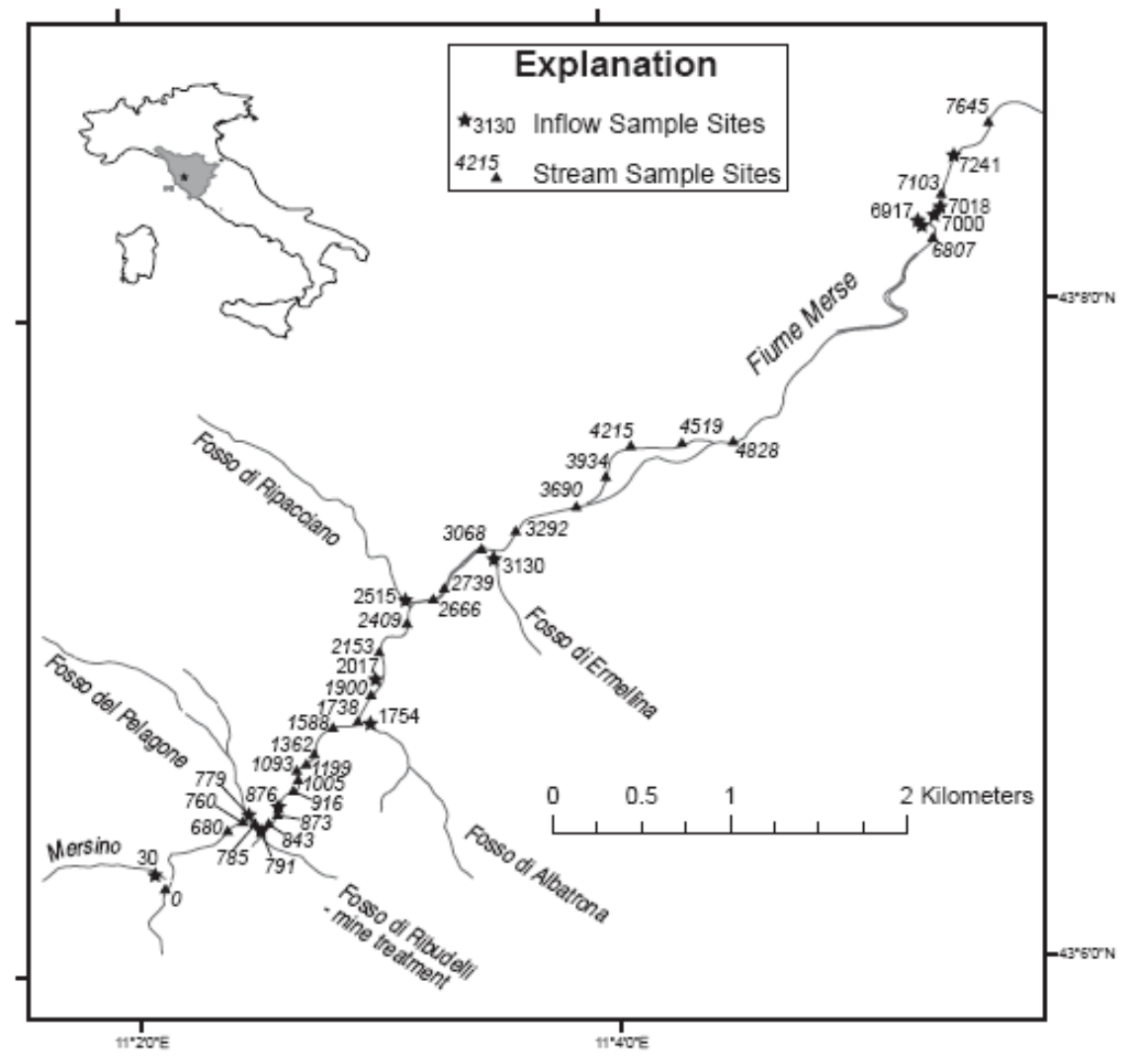

Figure 1. Study area with location of the sampling points. 
and is not a source of base metals to the Merse. However, mine wastes throughout the catchment continue to contribute metals to the stream. These exposed mine wastes, including waste-rock dumps, flotation tailings, and metallurgical wastes have been described by Benvenuti et al. (1997). The wastes are subject to erosion and have been flushed to the stream by storm runoff. In support of the Regione Toscana, a spatially detailed sampling of stream and inflow sites occurred before and during storm runoff in September 2006. Results of the sampling, reported here, provide the opportunity for a detailed quantification of changes that occurred in the stream as a result of storm runoff.

The Merse River begins more than $1 \mathrm{~km}$ upstream from the study reach indicated in Figure 1 . The storm comparison addressed here includes samples beginning at $760 \mathrm{~m}$ and ending at 3,934 $\mathrm{m}$. Samples upstream and downstream from that reach were part of a companion study. The injection of $\mathrm{Br}$ tracer was at $680 \mathrm{~m}$, and downstream at $791 \mathrm{~m}$ the mine-treatment inflow, combined with Fosso di Ribudelli, enters the Merse. From 873 $\mathrm{m}$ to about $1,200 \mathrm{~m}$, substantial ground-water inflow occurred, contributing water that was affected by weathering of sulfides in roaster-fine piles along the left bank (downstream orientation). Three additional tributaries included Fosso di Albatrona at 1,754 m, Fosso di Ripacciano at 2,515 m, and Fosso di Ermellina at $3,130 \mathrm{~m}$.

\section{Methods}

Quantification of metal loading from mining supports the process of making decisions about stream remediation because sources can only be compared based on their loading. Our approach to quantification of metal load relies on detailed spatial sampling of stream and inflow sites (synoptic sampling) and tracer injection to quantify streamflow along a study reach (Kimball et al., 2002). Traditionally, loading of solutes from a catchment has been quantified at the outlet of the catchment (Fig. 2a), a successful approach for many applications. However, when many possible sources of metal loading occur in a catchment, a detailed approach that extends up into the catchment is needed to allow comparison of the various sources. Our approach is to identify all the visible inflows that may represent sources of loading, and then bracket the inflows with stream samples to allow for mass balance calculations (Fig. 2b). Additional stream samples help quantify inflow of ground water. Combining a longitudinal profile of streamflow, calculated by tracer dilution, with spatially detailed samples of stream and inflow chemistry allows the calculation of mass-loading profiles to detect and compare metal sources and to quantify processes affecting metal transport. This is accomplished by designing a field-scale experiment (Kimball et al., 2003). Figure 1 indicates the substantial number of synoptic samples for this study of the Merse.

(a)

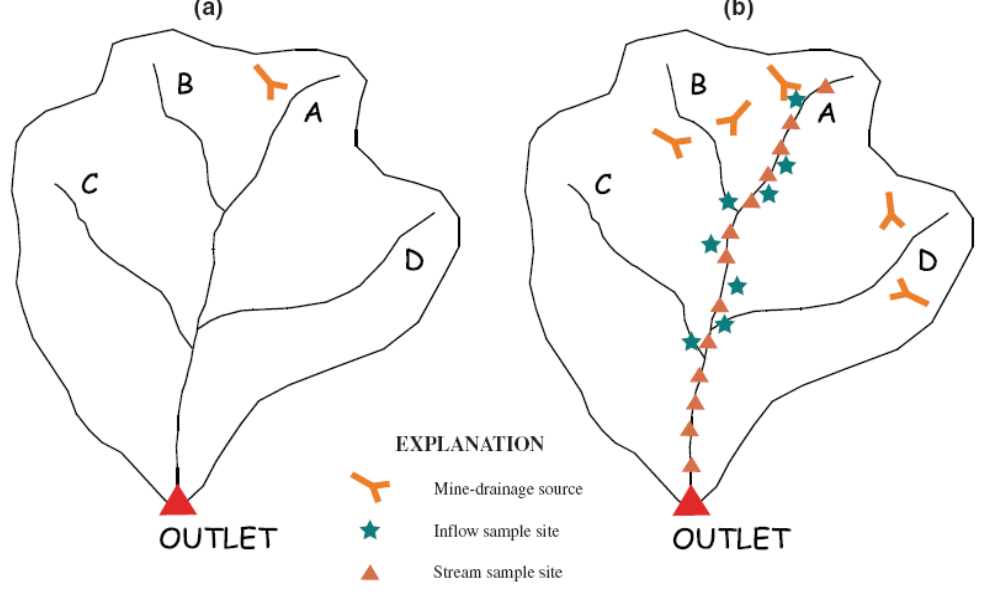

Figure 2. Sampling design for (a) a single-sample approach at the outlet of a catchment versus (b) detailed multiple-sample, synoptic sampling to quantify loading from multiple sources of metals in a catchment.

Samples were obtained using standard USGS methods (Ward and Harr, 1990) and methods previously described by Kimball et al. (2003). Only 3 filtered $(0.45-\mu \mathrm{m}$ filtration) samples were obtained during the pre-storm sampling, all the rest were total-recoverable samples, which is an unfiltered, acidified sample. The acidification results in the dissolution of $\mathrm{Al}, \mathrm{Fe}$, and $\mathrm{Mn}$ colloids and release of any metals that might be sorbed to them. Both filtered and total-recoverable samples were obtained during the storm sampling. The suspended colloids during the storm resulted in the formation of a filter cake on the in-line capsule filters and the effective pore size for the filtered sample most likely was much less than $0.45 \mu \mathrm{m}$. Many metal concentrations were determined, but this short discussion will be limited to changes in streamflow, $\mathrm{Cu}$, and $\mathrm{Mn}$. 


\section{Results and Discussion}

A continuous injection of $\mathrm{Br}$ tracer was initiated two days prior to synoptic sampling. The pre-storm profile of $\mathrm{Br}$ indicates the locations where both ground and surface inflows caused increases in streamflow (Fig. 3a). The corresponding streamflow, calculated from the Br dilution (Kilpatrick and Cobb, 1985), indicates the steadily increasing streamflow downstream during pre-storm conditions (Fig. 3b). The storm started about 07:00 hours the day of synoptic sampling, with heavy rainfall, and the resulting variation of bromide was very different. Downstream from 2,739 $\mathrm{m}$, the pre-storm and storm $\mathrm{Br}$ concentrations were similar, indicating that the storm wave had not arrived downstream when those samples were collected. However, the small difference in $\mathrm{Br}$ concentrations downstream from 2,739 $\mathrm{m}$ indicates a small increase in streamflow before the larger storm wave reached that section of the stream. Upstream from 2,739 m, however, Br concentration was lower, indicating greater streamflow upstream (Fig. 2a). The corresponding streamflow shows that the peak in streamflow for our synoptic sampling occurred at $1,738 \mathrm{~m}$ (Fig. 2b). The storm wave, as we sampled by the synoptic profile, was not instantaneous; the wave was moving downstream as we sampled downstream to upstream. Thus, the streamflow and subsequent loading profiles during the storm represent a wave with a rising limb from $2,739 \mathrm{~m}$ to the peak at $1,738 \mathrm{~m}$ and then a falling limb from the peak to $760 \mathrm{~m}$.

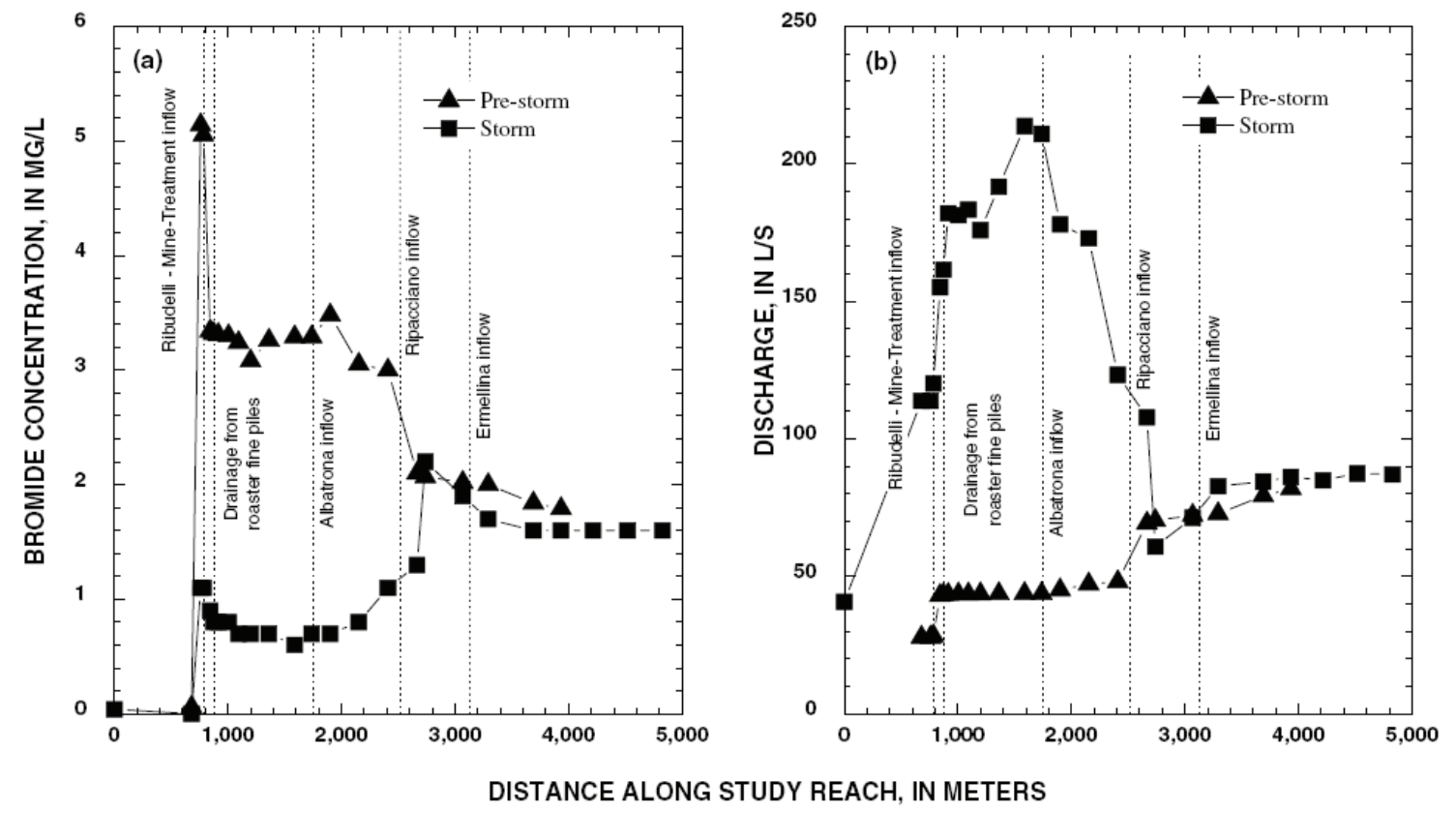

Figure 3. Variation of (a) bromide concentration and (b) calculated streamflow with distance along the study reach, Merse River, September 2006.

Variations of $\mathrm{Cu}$ and $\mathrm{Mn}$ concentrations differed substantially both before and during the storm (Fig. 4a and 4b). The strong affinity of $\mathrm{Cu}$ for transport in the colloidal Fe phase at near-neutral $\mathrm{pH}$, which occurred both before and during the storm, is evident in the difference between filtered and total $\mathrm{Cu}$ concentrations (Schemel et al., 2000; Smith, 1999). Manganese, on the other hand, was transported mostly in the aqueous phase. The highest inflow concentrations of both $\mathrm{Cu}$ and $\mathrm{Mn}$ were in samples of drainage from the roaster-fine piles at $876 \mathrm{~m}$. Before the storm, $\mathrm{Cu}$ concentration decreased substantially downstream from the mine-treatment inflow at 843 $\mathrm{m}$; Mn concentration did not. Both metal concentrations increased substantially between $843 \mathrm{~m}$ and $1,005 \mathrm{~m}$. Slight increases occurred between $1,005 \mathrm{~m}$ and $1,738 \mathrm{~m}$, and then both concentrations decreased downstream from that point. During the storm, most of the increase in total-recoverable Mn concentration was from the increase in filtered $\mathrm{Mn}$ (Fig. 4b). For total-recoverable $\mathrm{Cu}$ concentration, however, only a small amount of the increase was from filterable $\mathrm{Cu}$ (Fig. 4a). Filterable $\mathrm{Cu}$ concentrations did not exceed chronic toxicity levels before or during the storm despite the great increase in total-recoverable concentration. Ahead of the storm wave, both $\mathrm{Cu}$ and $\mathrm{Mn}$ total-recoverable concentrations were greater than before the storm (downstream from $2,739 \mathrm{~m}$ ). Concentrations of both metals increased on the rising limb of the flood wave, from 2,739 $\mathrm{m}$ to 1,738 $\mathrm{m}$, and then decreased on the falling limb of the storm wave from 1,738 $\mathrm{m}$ to $760 \mathrm{~m}$. On the most upstream end of the storm wave, both $\mathrm{Cu}$ and $\mathrm{Mn}$ concentrations were lower than during pre-storm conditions. The storm pattern suggests that there was a flush of the metals by the storm wave, increasing concentrations above pre- 
storm levels, and then dilution by the latter part of the storm wave. The flushing actually began in front of the measurable storm wave. Immediately downstream from the mine-treatment inflow, $\mathrm{Cu}$ concentrations did not decrease during the storm like they did before the storm. These changes are quantified by the load profiles for $\mathrm{Cu}$ and $\mathrm{Mn}$.

Pre-storm, steady-state loading profiles give the baseline conditions for evaluating changes from the storm. Copper loading at the beginning of the study reach was 7 percent of the cumulative total loading that was measured along the study reach; Mn loading was 27 percent (Fig. 4c and 4d). This indicates upstream sources of both metals. A substantial pre-storm difference between $\mathrm{Cu}$ and $\mathrm{Mn}$ loads occurred downstream from the minetreatment inflow where $\mathrm{Cu}$ load decreased but $\mathrm{Mn}$ load did not. As noted, this behaviour reflects the sorption of $\mathrm{Cu}$ to the hydrous $\mathrm{Fe}$ oxides that are contributed to the stream from Fosso di Ribudelli and that form in the stream with the inflow of the $\mathrm{pH} 8.1$ water from the mine treatment. Loads of $\mathrm{Cu}$ and $\mathrm{Mn}$ increased substantially between $843 \mathrm{~m}$ and $1,005 \mathrm{~m}$, which reflects the contribution from drainage affected by the roaster-fine piles. Downstream from the loading from the roaster piles, both $\mathrm{Cu}$ and $\mathrm{Mn}$ loads increased consecutively at $1,588 \mathrm{~m}$ and 1,738 m, and then $\mathrm{Cu}$ load increased again at 3,068 m. Downstream from 3,068 m, both loads decreased, most likely as Fe colloidal material settled from the stream.
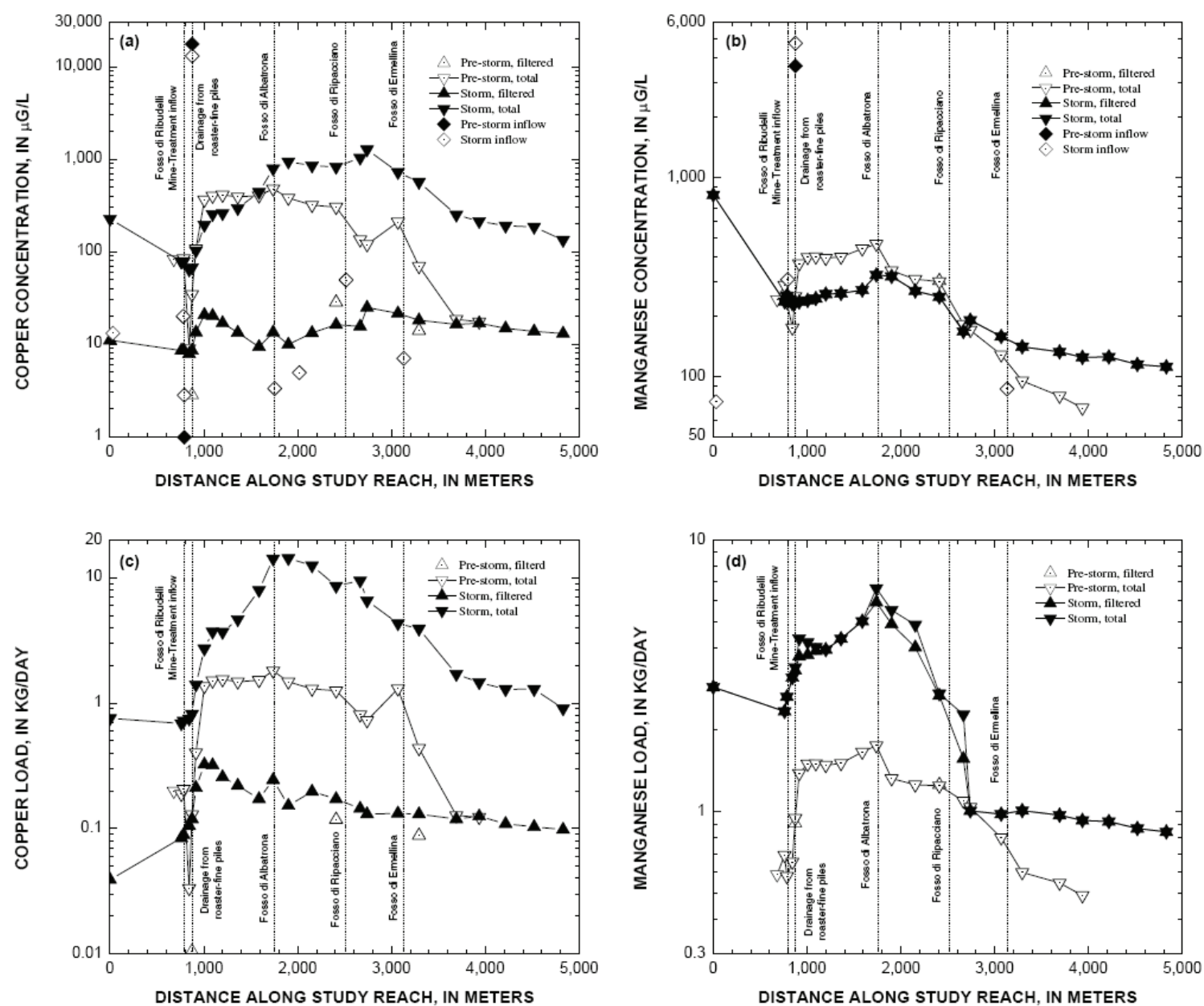

Figure 4. Variation of (a) copper concentration, (b) manganese concentration, (c) copper load, and (d) manganese load with distance along the study reach, Merse River, September 2006.

Storm runoff greatly increased the total-recoverable load at the beginning of the study reach. The comparison between the pre-storm load at $760 \mathrm{~m}$ and the storm-wave peak at 1,738 $\mathrm{m}$ indicates an increase more than 70 times greater for $\mathrm{Cu}$ and 9 times greater for $\mathrm{Mn}$. Sources of the increased load include metal-bearing particulate matter washed from stream banks, remobilization of particulates (mostly colloids) from the streambed, and increased streamflow from ground-water inflows, but these three sources cannot be distinguished in their individual contributions to the total-recoverable load. Downstream from the storm wave, which starts at 2,739 $\mathrm{m}$, 
both $\mathrm{Cu}$ and $\mathrm{Mn}$ loads were greater than pre-storm loads (Fig. 4c and 4d), even though the increase in streamflow was small (Fig. 3b). Total-recoverable $\mathrm{Cu}$ load increased more, relative to Mn load, downstream from the storm wave, most likely because it would be part of the colloids stirred up from the streambed by a small increase in streamflow. As the main storm wave increased between $2,739 \mathrm{~m}$ to $1,738 \mathrm{~m}$, total recoverable $\mathrm{Cu}$ load and both total and filtered $\mathrm{Mn}$ loads increased substantially. The large increase cannot be divided between material flushed from the banks and material resuspended from the streambed; both sources certainly contribute. The most notable case of resuspension occurred at $843 \mathrm{~m}$. Pre-storm $\mathrm{Cu}$ load downstream from the mine-treatment inflow decreased there, but during the receding limb of the storm wave, no loss of $\mathrm{Cu}$ load occurred.

Only 3 filtered samples were obtained during the pre-storm synoptic sampling. In comparison to corresponding storm samples, the increase in filtered load of $\mathrm{Cu}$ was much less than the increase in total-recoverable $\mathrm{Cu}$ load. At $843 \mathrm{~m}$ the increase was from 0.01 to $0.12 \mathrm{~kg}$ /day; the small load before the storm resulted from the removal of $\mathrm{Cu}$ at that site. At $2,409 \mathrm{~m}$ the increase was from 0.12 to $0.17 \mathrm{~kg}$ /day and at 3,292 $\mathrm{m}$ the increase was from 0.09 to $0.13 \mathrm{~kg} /$ day.

\section{Conclusions}

Having detailed synoptic-sampling and tracer-injection experiments on consecutive days before and then during a storm provides a unique opportunity to quantify the effects of storm runoff in a catchment affected by mining. The bromide tracer, injected at a constant rate on both days, provides quantification of streamflow and the detailed synoptic sampling provides the chemistry to quantify loading profiles. The synoptic sampling during the storm defined a storm wave moving downstream. Both $\mathrm{Cu}$ and $\mathrm{Mn}$ total-recoverable loads increased in advance of the storm wave as a result of a small increase of streamflow that may have stirred up colloidal material from the streambed. The rising limb of the storm wave brought a large increase in total-recoverable loads of $\mathrm{Cu}$ and $\mathrm{Mn}$, and the load was greatest at the peak of the storm wave. The falling limb of the storm wave caused dilution of $\mathrm{Cu}$ and $\mathrm{Mn}$ concentrations, but their total-recoverable loads were still much greater than the pre-storm loads. Although these metal loads increase substantially during the storm, the concentrations of $\mathrm{Cu}$ and $\mathrm{Mn}$ did not increase to toxic levels. The substantial concentrations of Fe colloidal material transported by the storm would likely have more impact on organisms by sediment overload than the slight increase in filtered concentrations of metals.

\section{Acknowledgements}

This work was supported by Regione Toscana and the U.S. Geological Survey Toxic Substances Hydrology Program.

\section{References}

Benvenuti M., Mascaro I., Corsini F., Lattanzi P., Parrini P., Tanelli G. (1997). Mine waste dumps and heavy metal pollution in abandoned mining district of Boccheggiano (Southern Tuscany, Italy). Environmental Geology 30, 238-243.

Kilpatrick F.A., Cobb E.D. (1985). Measurement of discharge using tracers. U.S. Geological Survey Techniques of Water-Resources Investigations, Book 3, Chapter A16, 27 p.

Kimball B.A., Runkel R.L., Walton-Day K. (2003). Use of field-scale experiments and reactive solute-transport modelling to evaluate remediation alternatives in streams affected by acid mine drainage. In Environmental aspects of mine wastes (eds. J. L. Jambor, D. W. Blowes, and A. I. M. Ritchie). Mineralogical Association of Canada, Vancouver, British Columbia, 261-282.

Kimball B.A., Runkel R.L., Walton-Day K., Bencala K.E. (2002). Assessment of metal loads in watersheds affected by acid mine drainage by using tracer injection and synoptic sampling: Cement Creek, Colorado, USA. Applied Geochemistry 17, 1183-1207.

Schemel L.E., Kimball B.A., Bencala K.E. (2000). Colloid formation and metal transport through two mixing zones affected by acid mine drainage near Silverton, Colorado. Applied Geochemistry 15, 1003-1018.

Smith K.S. (1999). Metal Sorption on Mineral Surfaces: An Overview with Examples Relating to Mineral Deposits. In The Environmental Geochemistry of Mineral Deposits Part. A: Processes, Techniques, and Health Issues (eds. G. S. Plumlee and M. J. Logsdon). Society of Economic Geologists, Littleton, Colorado, 161-182. Ward J.R., Harr C.A. (1990). Methods for collection and processing of surface-water and bed-material samples for physical and chemical analyses. U.S. Geological Survey Open-File Report 89-140, 71 p. 